\title{
Endovascular Treatment of a Lenticulostriate Artery Aneurysm with N-butyl Cyanoacrylate
}

\author{
Ramiro Larrazabal, David Pelz, J. Max Findlay
}

\begin{abstract}
Background: Aneurysms arising from lenticulostriate artery branches in moyamoya-type disease are challenging lesions to treat, due to their fragility and deep location. Surgery is difficult and endovascular options may be limited. Methods: A 57-year-old woman presented with a right ganglionic parenchymal hemorrhage due to a ruptured lenticulostriate artery aneurysm associated with ipsilateral middle cerebral artery occlusion. The aneurysm and parent feeding artery were occluded using endovascular injection of N-butyl cyanoacrylate. Results: The aneurysm was successfully obliterated and although some glue did enter the more distal middle cerebral artery, there was no change in the patient's neurologic status. Conclusions: In highly selected cases where lenticulostriate aneurysms cannot be directly accessed for surgery or endovascular coiling, obliteration with liquid acrylic glue may be considered as a therapeutic option.
\end{abstract}

RÉSUMÉ: Traitement endovasculaire par le N-butyl cyanoacrylate d'un anévrisme artériel lenticulostrié. Introduction: Les anévrismes qui prennent naissance sur des branches de l'artère lenticulostriée dans la maladie de type moyamoya sont des lésions difficiles à traiter à cause de leur fragilité et de leur site profond. La chirurgie est difficile et les options endovasculaires limitées. Méthodes: Une femme âgée de 57 ans a consulté pour une hémorragie parenchymateuse ganglionaire droite due à la rupture d'un anévrisme de l'artère lenticulostriée associé à une occlusion de l'artère cérébrale moyenne ipsilatérale. L'anévrisme et l'artère nourricière ont été occlus au moyen d'une injection endovasculaire de N-butyl cyanoacrylate. Résultats: L'anévrisme a été oblitéré avec succès et, bien qu'un peu de colle ait pénétré dans l'artère cérébrale moyenne distale, il n'y a pas eu de changement du statut neurologique de la patiente. Conclusions: Dans des cas bien choisis où les anévrismes lenticulostriés sont hors d'atteinte de la chirurgie ou de la mise en place d'un serpentin par voie endovasculaire, l'oblitération par une colle acrylique liquide peut être une option thérapeutique valable.

Can. J. Neurol. Sci. 2001; 28: 256-259

Direct surgery for aneurysms located in the basal ganglia region, arising from moyamoya-type vessels, is difficult because of the danger of damaging fragile collateral vessels. Surgery is not recommended for small aneurysms located within the basal ganglia. ${ }^{1}$ Platinum coils and particles have been used to treat peripheral cerebral aneurysms associated with moyamoya disease. ${ }^{2,3}$ We performed embolization of a lenticulostriate artery aneurysm associated with ipsilateral middle cerebral artery (MCA) occlusion using N-butyl cyanoacrylate (NBCA). We believe this is the first report of this treatment for aneurysms arising from moyamoya-type vessels.

\section{CASE RePORT}

A 57-year-old female presented with witnessed loss of consciousness before a fall. On admission, she had decerebrate posturing and her Glasgow Coma Scale (GCS) was 4. A computed tomography (CT) scan revealed extensive intraparenchymal right ganglionic and intraventricular hemorrhage (Figure 1A). The patient underwent an urgent cerebral angiogram. This demonstrated a moyamoya-type pattern, which consisted of right MCA M1 occlusion and ipsilateral moyamoyatype vessels (Figure 1B). The remainder of the middle cerebral territory on the right was collateralized from leptomeningeal vessels from the right anterior (ACA) and posterior cerebral (PCA) arteries. The rest of the vessels were normal. Over the following days, the patient gradually regained consciousness and began to purposefully move the right side, but remained paralysed on the left.

A follow-up angiogram was done 17 days after admission. This clearly demonstrated a $4 \mathrm{~mm}$ aneurysm arising from one prominent lenticulostriate branch of the right MCA (Figure 2A,B). This was

From the Department of Diagnostic Radiology and Clinical Neurological Sciences, University of Western Ontario, London, Ontario, (RL, DP); Division of Neurosurgery, University of Alberta, MacKenzie Health Sciences Centre, Edmonton, Alberta (JMF) Canada.

Received December 18, 2000. ACCEPTED In Final Form April 9, 2001. Reprint requests to: David M. Pelz, Department of Diagnostic Radiology, London Health Sciences Centre, University Campus, 339 Windermere Road, PO Box 5339 , London, Ontario, Canada N6A 5A5 


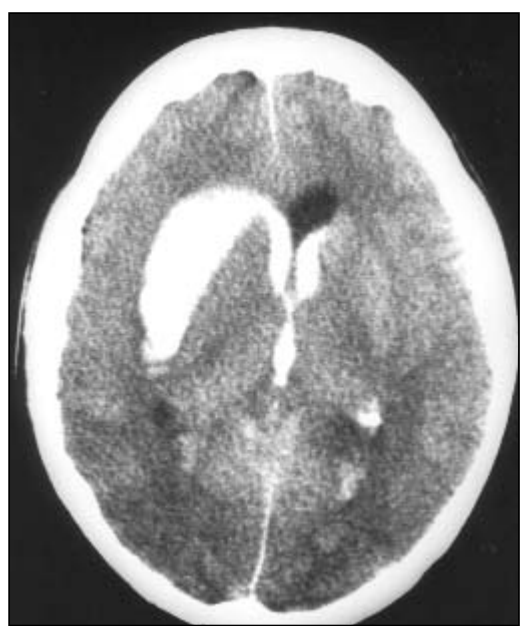

Figure 1A: Noncontrast computed tomography $(C T)$ scan on the day of admission demonstrates intraparenchymal right ganglionic and intraventricular hemorrhage.

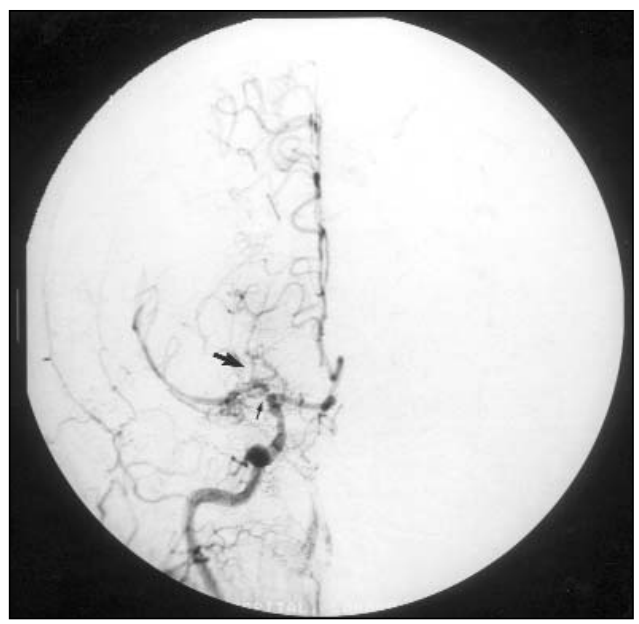

Figure 1B: Right common carotid digital subtraction angiogram (DSA), anteroposterior (AP) projection, on the same day reveals complete occlusion of the middle cerebral artery (MCA) at the MI segment (small arrow) and ipsilateral moyamoya-type vessels (large arrow). considered to be the source of bleeding. Due to the difficulties associated with surgery in this area, endovascular treatment was performed on day 21. At this time, the small aneurysm originating from the largest lenticulostriate vessel was 1-2 $\mathrm{mm}$ larger than on the previous cerebral angiogram (Figure 3).

A Tracker-10*microcatheter (*Boston Scientific/Target - Fremont, CA) was advanced through a 6 French introducing catheter, into the distal right internal carotid artery. Probing with a Transcend 10* soft tip guide wire, resulted in supraselective catheterization of the large lenticulostriate feeder to the aneurysm.

A supraselective contrast injection showed good filling of this tortuous lenticulostriate branch which filled not only the aneurysm but also a leash of small end arteries supplying the right lentiform nucleus (Figure 4).

There was continuity of this vessel with the more distal right MCA. An injection of approximately $0.3 \mathrm{cc}$ of NBCA diluted 2:1 with lipiodol was then made. Most of the glue deposited within the lenticulostriate branch and the aneurysm. A small amount of glue did pass into the more distal horizontal segment of the right MCA but this was non-occlusive. A subsequent right internal carotid arteriogram showed complete occlusion of the lenticulostriate branch and the aneurysm (Figure 5A,B). There was still visualization of an extensive collateral network filling the distal M1 segment of the right MCA, although the flow was less in the sylvian segment as compared to the pre-embolization injection. Extensive leptomeningeal supply from the right ACA and PCA was unchanged. Following this, there was no worsening of the patient's neurological status as she remained completely hemiplegic on the left side.

There was no significant change in the CT performed after the embolization. This showed evolution of the intracerebral hemorrhage with low density in the right basal ganglia region. Casts of embolic material were present in the right M1 segment. The ventricular hemorrhage had resolved and ventricular size was normal.

Before being discharged, after 24 days of hospitalization, the patient was bright and alert. She followed commands briskly on the right side. She remains spastic and hemiparetic on the left side. She has been in rehabilitation since discharge from the hospital.

\section{DiscuSSION}

Aneurysms of lenticulostriate arteries are relatively rare. They have been demonstrated in hypertensive patients, patients with moyamoya disease and also in a patient with systemic lupus erythematosus. ${ }^{4}$ These aneurysms may also be seen on feeding arteries in patients with deep ganglionic-thalamic AVMs. In the presence of a major intracranial vessel occlusion, aneurysms of the lenticulostriate arteries are likely associated with moyamoya disease. In classical moyamoya disease, prominent ganglionic collateral vessels are usually associated with bilateral terminal internal carotid artery occlusion. Our case most likely represented a spontaneous MCA occlusion with development of moyamoya-like ganglionic collateral vessels. The lenticulostriate aneurysms in both conditions appear to behave similarly.

The incidence of aneurysms associated with moyamoya disease is 1.5 to $12.9 \% .^{5}$ Kawaguchi et $\mathrm{al}^{1}$ demonstrated that $18 \%$ of 131 aneurysms associated with moyamoya disease were located in the basal ganglia. There have been 24 reported cases of spontaneous MCA occlusion. Nine of these cases presented with cerebral aneurysms located in abnormal collateral vascular networks and all the reported cases presented with cerebral hemorrhage at their onset.

Takahashi et $\mathrm{al}^{6}$ reported a case of rapidly growing cerebral aneurysm in the basal collateral vascular network associated with spontaneous MCA occlusion in a 54-year-old female patient. The aneurysm disappeared spontaneously shortly after performing superficial temporal artery-middle cerebral artery (STA-MCA) anastomosis. It has been suggested that STA-MCA anastomosis in moyamoya disease reduces the incidence of transient ischemic attacks, and also decreases the hemodynamic stress on the abnormal basal vascular network and results in reduction in size or thrombosis of the aneurysms. ${ }^{6}$ However, Ikezaki et $\mathrm{al}^{7}$ have found that nearly $18 \%$ of the patients with 


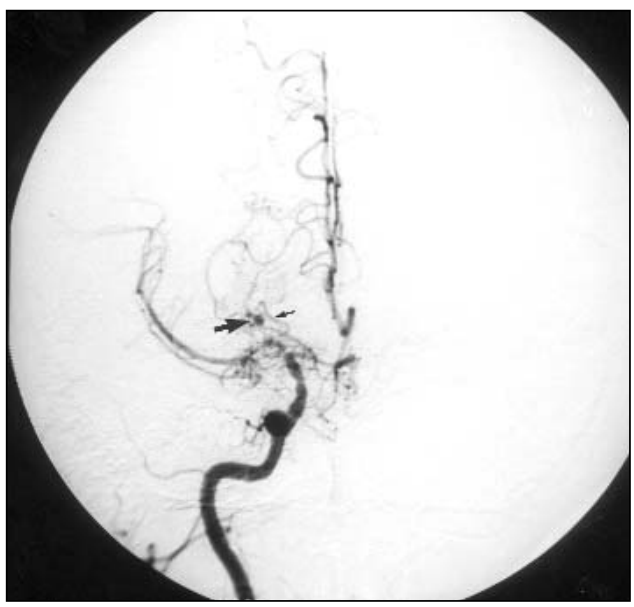

Figure 2A: Right common carotid DSA, AP projection on the 17th day post-admission demonstrates the MCA M1 occlusion, ipsilateral moyamoya-type vessels and a $4 \mathrm{~mm}$ aneurysm (large arrow) arising from the most prominent lenticulostriate branch (small arrow).

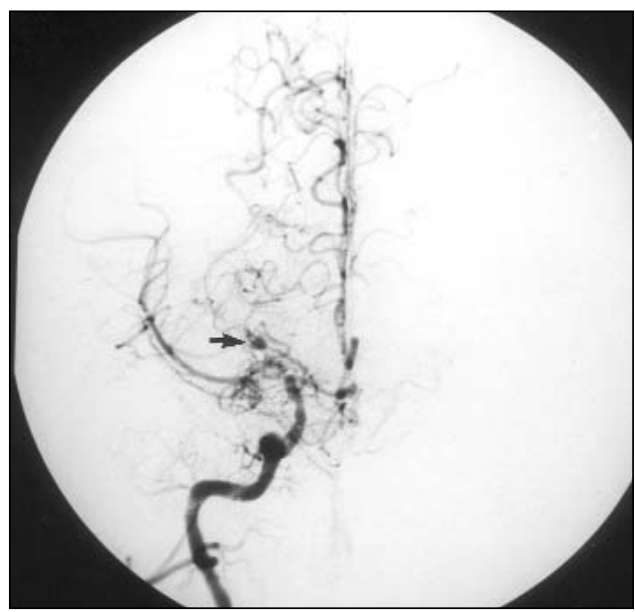

Figure 3: Right common carotid DSA, AP projection on the 21st day of admission shows slight increase in size of the aneurysm (arrow).

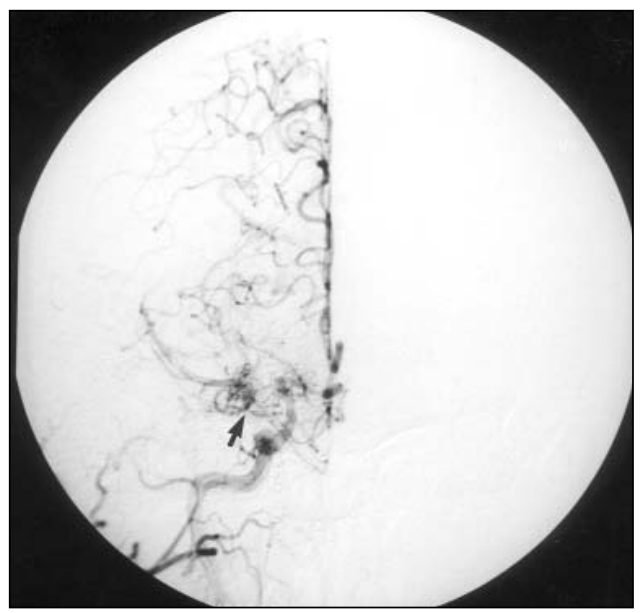

Figure 5A: Right common carotid DSA, AP view after the embolization indicates complete obliteration of the lenticulostriate branch and the aneurysm. An extensive collateral network is seen filling the distal horizontal segment of the right MCA (arrow).

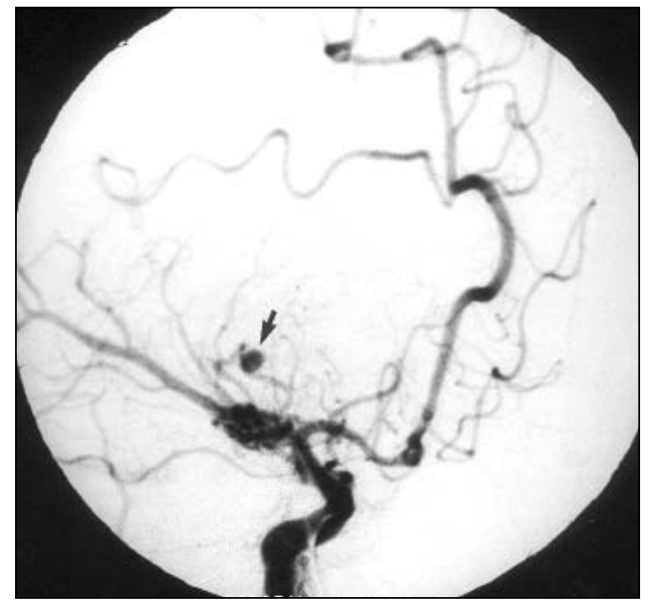

Figure 2B: Magnified oblique view of the aneurysm (arrow).

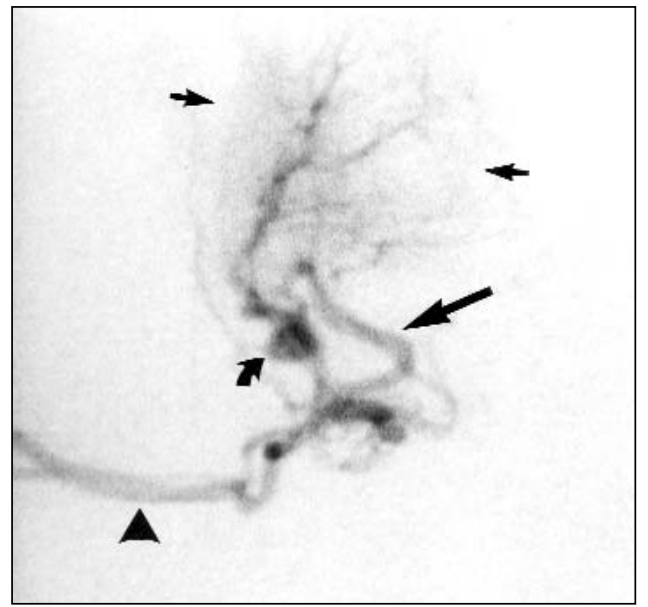

Figure 4: Supraselective contrast injection of the large lenticulostriate artery, AP view shows filling of this tortuous vessel (large arrow) and also filling of multiple small end arteries (small arrows) which supply the right lentiform nucleus. The aneurysm is well seen (curved arrow), as is the distal M1 segment of the MCA (arrowhead).

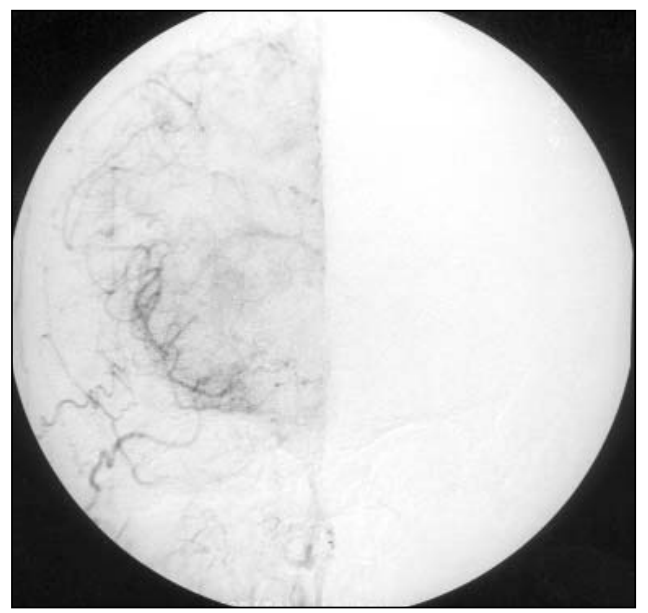

Figure 5B: Extensive leptomeningeal supply from the right $A C A$ and $P C A$ is appreciated later on the same angiogram, with further reconstitution of distal sylvian MCA branches. 
hemorrhagic moyamoya disease experienced rebleeding regardless of the treatment modalities. The prognosis of rebleeding in patients with hemorrhagic moyamoya disease is extremely poor, and several authors have come to the conclusion that there is still no clear evidence that revascularization surgery significantly prevents rebleeding in these patients. ${ }^{7,8,9}$ Factors related to rebleeding and poorer outcome are sex (with women being more susceptible), massive intracranial hemorrhage and early recurrence. We believe that the risk of rebleeding in our patient was high, given that she was a female, with a massive intracranial hemorrhage and with a rapidly growing cerebral aneurysm associated with spontaneous MCA occlusion. A revascularization procedure was not a promising option for treatment and it was not considered.

A direct surgical approach has been thought to be necessary in treating aneurysms in patients with moyamoya disease and associated subarachnoid hemorrhage. ${ }^{10}$ However, it has been shown that compression of the perforating vessels around aneurysms of the parent artery during surgical clipping can induce circulatory compromise leading to postoperative hemiplegia or severe brain edema. ${ }^{10}$ Furthermore, excessive hypotension and decreased $\mathrm{PCO}_{2}$ in the blood during surgery must be avoided, because patients with moyamoya disease are particularly susceptible to cerebral ischemia. In a review of 111 cases of aneurysms associated with moyamoya disease, Kawaguchi et $\mathrm{al}^{1}$ have suggested that direct surgery is not recommended for aneurysms found in the basal ganglia or in the collateral vessels. In our case, the fragility of adjacent vessels and the danger of damaging important collateral vessels made us consider an endovascular approach.

Guglielmi electrically detachable coils (GDC) have been used in the treatment of major artery aneurysms associated with moyamoya disease. ${ }^{11}$ There has been a case report of endovascular treatment using platinum coils of a peripheral artery aneurysm associated with moyamoya disease. ${ }^{2}$ Endovascular treatment of a small aneurysm of the right anterior choroidal artery was performed with preservation of the parent artery. We considered this a good treatment option, but we were unable to place our microcatheter far enough into the feeding artery to safely deploy a coil.

Endovascular embolization of rapidly growing aneurysms arising from moyamoya-type vessels using the mixture of NBCA and lipiodol has, to our knowledge, not been reported. We used this approach because the microcatheter could only be placed in the proximal segment of the parent vessel and not into the aneurysm. We recognize the risk of NBCA either refluxing into the proximal MCA or occluding collateral channels but, given the fact that the patient was already hemiplegic on the left side, we believed that little or no further clinical deterioration could be caused with a slow and careful injection of a small volume of liquid embolizing agent. We believed that urgent treatment of the unstable aneurysm was necessary to prevent further bleeding.

We do not recommend this type of treatment as a routine practice in aneurysms arising from moyamoya-type vessels. This option can be considered when the aneurysm can not be directly accessed for coil treatment and the likelihood of causing further neurologic injury is low.

\section{REFERENCES}

1. Kawaguchi S, Sakaki T, Morimoto T, Kakizaki T, Kamada K. Characteristics of intracranial aneurysms associated with moyamoya disease. A review of 111 cases. Acta Neurochir (Wien) 1996;138(11):1287-1294.

2. Sugiura Y, Matsuzawa Y. Endovascular treatment using platinum coil of a peripheral artery aneurysm associated with moyamoya disease: case report. No Shinkei Geka 1998;26(1):73-77.

3. Maekawa M, Nemoto S, Awaya S, Teramoto A. Moyamoya disease with intraventricular hemorrhage due to rupture of lateral posterior choroidal artery aneurysm: case report. No Shinkei Geka 1999;27(11):1047-1051.

4. Kidoguchi J, Chiba M, Murakami T, et al. A case of systemic lupus erythematosus associated with an aneurysm of the lenticulostriate artery. No Shinkei Geka 1987;15(11):1221-1225.

5. Shibuya P, Hayashi N. A case of posterior cerebral artery aneurysm associated with idiopathic bilateral internal carotid artery occlusion: case report. Surg Neurol 1999;52:617-622.

6. Takahashi M, Fujimoto T, Suzuki R, et al. A case of spontaneous middle cerebral artery occlusion associated with a cerebral aneurysm angiographically disappearing after STA-MCA anastomosis. No Shinkei Geka 1997;25(8):727-732.

7. Ikezaki K, Fukui M, Inamura $\mathrm{T}$, et al. The current status of the treatment for hemorrhagic type moyamoya disease based on a 1995 nationwide survey in Japan. Clin Neurol Neurosurg 1997;99(S2):183-186.

8. Choi JU, Kim DS, Kim EY, Lee KC. Natural history of moyamoya disease: comparison of activity of daily living in surgery and nonsurgery groups. Clin Neurol Neurosurg 1997;99(S2):11-18.

9. Yoshida Y, Yoshimoto T, Shirane R, Sakurai Y. Clinical course, surgical management, and long-term outcome of moyamoya patients with rebleeding after an episode of intracerebral hemorrhage. An extensive follow-up study. Stroke 1999;30:22722276.

10. Kodama N, Sato M, Sasaki T. Treatment of ruptured cerebral aneurysm in moyamoya disease. Surg Neurol 1996;46:62-66.

11. Massoud TF, Guglielmi G, Viñuela F, Duckwiler GR. Saccular aneurysms in Moyamoya disease: endovascular treatment using electrically detachable coils. Surg Neurol 1994;41:462-467. 